\title{
Biomarkers of exposure to low concentrations of benzene: a field assessment
}

\author{
C N Ong, P W Kok, H Y Ong, C Y Shi, B L Lee, W H Phoon, K T Tan
}

\begin{abstract}
Objective-To carry out a comprehensive field investigation to evaluate various conventional and recently developed biomarkers for exposure to low concentrations of benzene.

Methods-Analyses were carried out on environmental air, unmetabolised benzene in blood and urine, urinary trans, transmuconic acid, and three major phenolic metabolites of benzene: phenol, catechol, and hydroquinone. Validations of these biomarkers were performed on 131 never smokers occupationally exposed to the time weighted average benzene concentration of $0.25 \mathrm{ppm}$ (range, 0.01 to $3.5 \mathrm{ppm}$ ). Results-Among the six biomarkers studied, unmetabolised benzene in urine correlated best with environmental benzene concentration (correlation coefficient, $r=0.76$ ), followed by benzene in blood $(r=0.64)$. When urinary metabolites were compared with environmental benzene, trans, trans-muconic acid showed a close correlation $(r=0.53)$ followed by hydroquinone $(r=0.44)$, and to a lesser extent with urinary phenol $(r=$ 0.38). No correlation was found between catechol and environmental benzene concentrations. Although unmetabolised benzene in urine correlates best with benzene exposure, owing to serious technical drawbacks, its use is limited. Among the metabolites, trans, trans-muconic acid seems to be more reliable than other phenolic compounds. Nevertheless, detailed analyses failed to show that it is specific for monitoring benzene exposures below 0.25 ppm.
\end{abstract}

Conclusion-The overall results suggest that most of the currently available biomarkers are unable to provide sufficient specificity for monitoring of low concentrations of benzene exposure. If a lower occupational exposure limit for benzene is to be considered, the reliablity of the biomarker and the technical limitations of measurements have to be carefully validated.

(Occup Environ Med 1996;53:328-333)

Keywords: specificity; threshold limit values; biomonitoring

Benzene is an important component in petrol and is widely used in chemical, paint, and dye industries. The evidence for the association between exposure to benzene and leukaemogenic effect has been adequately reviewed. ${ }^{1}$ However, there is still much controversy on what level of exposure to benzene constitutes an acceptable risk. ${ }^{2}$ With new evidence on the risk of benzene associated with neoplasia, several national and international authorities have recently advised reduction of occupational benzene exposure. The European Community benzene directive calls for an action level of 1 ppm benzene and a limit value of $5 \mathrm{ppm}$ time weighted average. ${ }^{3}$ In some countries lower values have been adopted (Sweden, $0.5 \mathrm{ppm}$ ) or proposed (United States, ACGIH, $0 \cdot 1 \mathrm{ppm}^{4}$ ). Thus, studies on biological monitoring at these low concentrations of exposure are urgently needed.

Traditionally, the most common method used for biological monitoring of benzene exposure is based on measuring a metabolite of benzene, usually urinary phenol (PH). However, more recent studies have shown that measurement of phenol is considered to be unreliable, especially for low levels of benzene exposure. ${ }^{5}$ Analytical methods for the measurements of minor phenolic metabolites such as catechol $^{6}$ and hydroquinone, ${ }^{7}$ and unmetabolised benzene in blood and urine ${ }^{89}$ have also been developed recently. Most of these methods, however, have not been validated, especially for benzene concentrations of less than 5 ppm. ${ }^{5}$

S-phenylmercapturic acid has been shown to be more specific and sensitive than $\mathrm{PH}$ in the estimation of exposure. ${ }^{10}$ However, for measurement of S-phenylmercapturic acid, sophisticated gas chromatography-mass spectrophotometry (GC-MS) is required for adequate sensitivity, and is some way from being an efficient technique for routine monitoring. ${ }^{11}$ Trans, trans-muconic acid, a metabolite of trans, trans-mucoaldehyde has also been proposed as a biomarker for benzene exposure. ${ }^{12} 14$ Nevertheless, its use for benzene exposure of less than $5 \mathrm{ppm}$ has not been studied extensively.

If an exposure limit has to be considered, the most appropriate biological exposure index has first to be validated before it can be widely used. In an earlier study, ${ }^{15}$ we have shown that trans, trans-muconic acid was a useful biomarker for benzene exposure for concentrations of 1-68 ppm. In this paper we report the results of a follow up study designed to evaluate various biomarkers of benzene exposure in a much larger cohort exposed to benzene that ranged from 0.01 to $3.5 \mathrm{ppm}$. The exposure biomarkers studied included unmetabolised 
benzene in blood and urine; trans, transmuconic acid, a metabolite of the ring opening pathway, and three phenolic metabolites in urine, phenol, catechol, and hydroquinone.

\section{Materials and methods}

\section{SUBJECTS}

The study was conducted in five large petroleum refineries in Singapore from 1992 to 1994. Over 300 male workers from different job categories were randomly selected for this study. The response rate was over $95 \%$. Eleven workers with known heart, lung, liver, kidney, haematological, other chronic diseases, or currently under medication were excluded. Among the 290 selected for the investigation, 190 were never smokers and 95 were current or ex-smokers. As cigarette smoking affects the metabolism of benzene, ${ }^{16}$ the data of the 95 current or ex-smokers were not included in the present investigation (results will be presented elsewhere). Among the never smokers selected for the present study, none of them drank alcohol on a regular basis.

About $20 \mathrm{ml}$ urine samples from the end of a shift were collected and preserved with $200 \mu \mathrm{l}$ of $6 \mathrm{~N} \mathrm{HCl}$ and stored frozen at $-70^{\circ} \mathrm{C}$ until analysis. Venous blood $(5 \mathrm{ml})$ was also drawn from each subject at the end of the workshift. Sample were kept at $4^{\circ} \mathrm{C}$ until analysis. Among the exposed never smokers only about 80 workers agreed to have their blood taken. Both environmental and biological assessments were carried out at midweek. No respirators were used by any of the workers during their normal work activities, or on the day of sample collection. All the workers wore long sleeved cotton jacket throughout their workshifts and cotton gloves were used in the production and operation areas. Skin absorption is thus thought to be minimal.

Forty never smokers with no history of solvent exposure were used for evaluation of the analytical method and for comparison with the exposed group. Most of the non-exposed subjects were hospital staff or graduate students in the medical school. Based on seven environmental samplings conducted in various parts of the medical school, the time weighted average concentration of benzene in air was $14.2 \mathrm{ppb}$ (range 11-21 ppb). Blood samples were not collected from the controls.

\section{ENVIRONMENTAL AIR SAMPLES}

Individual exposure to benzene at the workplace was monitored with a $3 \mathrm{M}$ Organic Vapor Monitor (model 3500) throughout the whole workshift of eight hours. The diffusive samplers were attached to the collar or shirt pocket of the workers before they entered the plant. The samplers were detached at the end of the shift and stored at $-4^{\circ} \mathrm{C}$ until analysis. Owing to financial constraints, environmental monitorings were carried out on only $70 \%$ of the subjects, according to different job categories.

Measurement of benzene in the dosimeter was carried out within one week. An autosampler was used together with an integrator for the gas chromatographic determination of ben- zene. The injection volume was $2 \mu \mathrm{l}$. With the use of a photoionisation detector, a detection limit of $0.005 \mathrm{ppm}$ ( $5 \mathrm{ppb}$ ) could be achieved.

\section{MEASUREMENT OF BENZENE IN BLOOD AND} URINE

The analysis of unmetabolised benzene in blood and urine was carried out according to the headspace GC method of Kok and Ong. ${ }^{9}$ For the analysis, $1.0 \mathrm{ml}$ of blood or urine sample in a headspace vial containing chlorobenzene as an internal standard was incubated at $60^{\circ} \mathrm{C}$ for 30 minutes and $0.5 \mathrm{ml}$ headspace gas was used for GC analysis. Benzene was detected at 2.5 minutes with a silicone gum capillary column and a photoionisation detector. The detection limits for benzene in blood and urine were $0.3 \mathrm{nmol} / 1$ and $0.26 \mathrm{nmol} / 1$, respectively, with $1 \mathrm{ml}$ headspace injection volume. Samples were analysed within 24 hours after collection, as storage led to significant loss of benzene. ${ }^{9}$ The variations within a day for both analyses were generally less than $9 \%$.

In the present study, the unmetabolised benzene in urine was expressed as observed (nmol/l) without correction for urinary creatinine. Our preliminary data and several earlier studies $^{1718}$ have indicated that for biomonitoring of unmetabolised organic solvents it is not nessary to correct for urinary creatinine, which weakens the correlations with exposure (see review by Boeniger et al ${ }^{19}$ ). This is probably due to the extraction of unmetabolised volatile compounds, which is through tubular diffusion rather than the glomerular filtration of metabolites.

MEASUREMENT OF CATECHOL, HYDROQUINONE, AND PHENOL IN URINE

Urine samples were collected in polycarbonate bottles at the end of the workshift and stored at $-4^{\circ} \mathrm{C}$. Measurement of phenolic compounds in urine was carried out according to the method of Lee et $a^{7}$ with high performance liquid chromatography (HPLC) with variable wavelength flurometric detection. The recovery and reproducibility of this method were generally over $90 \%$. The results were presented after correction for creatinine concentration ( $\mathrm{mg} / \mathrm{g}$ creatinine). The creatinine was measured by an Abbott autoanalyser based on Jaffe's method.

\section{MEASUREMENT OF TRANS, TRANS-MUCONIC} ACID

Measurement of trans, trans-muconic acid was carried out with the HPLC method recently developed in our laboratory. ${ }^{13}$ The trans, transmuconic acid was detected at 10.2 minutes with an ultraviolet (UV)/visible spectrophotometer at wavelength $265 \mathrm{~nm}$. The detection limit was $125 \mathrm{pg}$. Analytical recovery and reproducibility generally exceeded $90 \%$.

\section{STATISTICAL ANALYSIS}

Statistical analysis was performed with the Statistical Package for Sociological Studies (SPSS) package (Windows version) on an IBM compatible personal computer. Data were analysed with consideration of the highly 
Table 1 Means (arithmetic ( $A M$ ) and geometric (GM)), SDs, and ranges of various variables studied

\begin{tabular}{llccc}
\hline Variable & $n$ & $A M(S D)$ & $G M$ (range) \\
\hline Air & benzene (ppb) & 131 & $246.00 \pm 60 \cdot 00$ & $44.00(11.00-3460)$ \\
Blood & benzene (nmol/) & $61^{\star}$ & $6.04 \pm 16.23$ & $1.78(0 \cdot 32-123 \cdot 2)$ \\
Urinary & benzene (nmol/) & $119^{\star}$ & $47 \cdot 10 \pm 186.00$ & $1.54(0.61-1531)$ \\
Urinary & phenol (mg/g creatinine) & 131 & $7 \cdot 89 \pm 11.73$ & $3.69(0.09-61.38)$ \\
Urinary & catechol (mg/g creatinine) & 131 & $1.63 \pm 1.34$ & $0.93(0.03-9 \cdot 16)$ \\
Urinary & $\begin{array}{l}\text { hydroquinone } \\
\text { (mg/g creatinine) }\end{array}$ & 131 & $0.47 \pm 0.49$ & $0.34(0.03-3.22)$ \\
Urinary & $\begin{array}{l}t, t \text {-muconic acid } \\
\text { (mg/g creatinine) }\end{array}$ & 131 & $0.34 \pm 0.90$ & $0.19(0.01-5.34)$ \\
\hline
\end{tabular}

*A total of 84 blood samples were collected, due to instrumentation problems some of the blood samples were not analysed within 24 hours. 10 Urine samples were too late for analysis and two were below the detection limit.

skewed distribution of several variables and environmental benzene concentrations; analyses on correlations were also carried out with logarithmic transformation of the data.

\section{Results}

Although analyses were conducted for most biomarkers of all 190 subjects, environmental monitorings were conducted on about $70 \%$ of the participants. Detailed investigations were thus carried out on the 131 workers together with the 40 non-exposed controls. Table 1 shows the means (arithmetic and geometric), SDs, and ranges of the various biological vari-

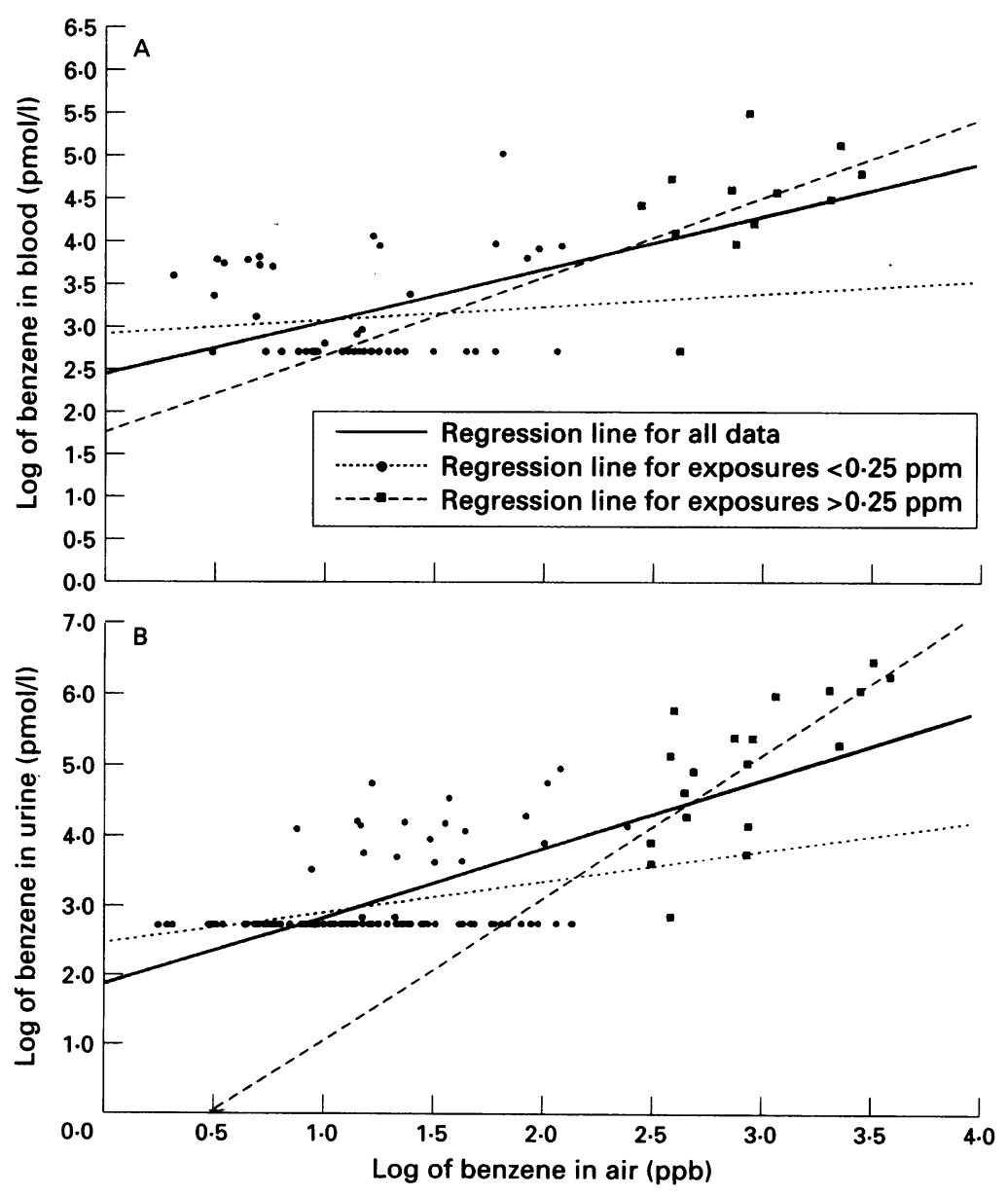

Figure 1 (A) Relation between unmetabolised benzene in blood and breathing zone air. $\log Y=0.67 \log X-0.77, n=61, r=0.64, P<0.05$. Points are individual values. For subjects exposed to $<0.25 \mathrm{ppm}, r=0.12, \mathrm{NS}$. For subjects exposed to $>0.25 \mathrm{ppm}$, $r=0 \cdot 44, N S)$. (B) Relation between unmetabolised benzene in urine and breathing zone $r=0.44, N S$.
air. $\log Y=0.60 \log X-0.48, n=119, r=0.76, P<0.001$. For subjects exposed to $<0.25 \mathrm{ppm}, r=0.35, P<0.05$. For subjects exposed to $>0.25 \mathrm{ppm}, r=0.71$, $P<0.01$. ables and environmental exposure concentrations. Most ( $96 \%)$ of the workers studied were exposed to benzene concentrations of $1 \mathrm{ppm}$ or below, with a mean concentration of 0.246 ppm. The concentrations of benzene in blood and benzene in urine were found to have rather wide variations, from 0.32 to 123.3 $\mathrm{nmol} / 1$ and 0.61 to $1531 \mathrm{nmol} / \mathrm{l}$, respectively. In contrast, the range of concentrations detected for hydroquinone seemed to be relatively small (table 1 ).

Figures 1 to 3 show the scatter diagrams between benzene concentrations in air and various exposure biomarkers of 131 workers for whom environmental exposure concentrations were available. Significant associations were noted between all the urinary biomarkers and benzene in breathing zone air, except urinary catechol (fig 2B). The best correlation with breathing zone air was benzene in urine (fig 1B, $r=0.76, \mathrm{P}<0.001$ ), followed by benzene in blood (fig 1A, $r=0.64, \mathrm{P}<0.01$ ). Among the phenolic metabolites, urinary hydroquinone showed the best correlation with atmospheric benzene (fig 2C, $r=0.44$, $P<0.01$ ), and to a lesser extent urinary phenol (fig $2 \mathrm{~A}, r=0.38, \mathrm{P}<0.05$ ). No significant association was noted between urinary catechol and environmental benzene (fig 2B). Figure 3 shows the correlation coefficient between benzene concentration in the breathing zone air and urinary trans, trans-muconic acid collected at the end of the shift, with $r=$ $0.53, P<0.01$.

When the data were categorised according to the mean concentration of benzene exposure $(0.25 \mathrm{ppm})$, the correlations were generally higher for those workers who were more intensively exposed. The results indicated that when the exposures were lower than $0.25 \mathrm{ppm}$ (mean exposure concentration of $0.12 \mathrm{ppm}$ ), the only biomarker that did show significant correlations with atmospheric benzene was benzene in urine. It was noted that although benzene in urine still maintained a good correlation with environmental benzene at lower levels of exposure, most of the concentrations detected were at the detection limit of 0.51 $\mathrm{nmol} / \mathrm{l}$ (510 pmol/1, fig 1B). A similar finding was noted for benzene in blood (fig 1A).

To evaluate the sensitivity and specificity of individual biomarkers, statistical tests were conducted on workers exposed to low benzene concentration, less than $0.25 \mathrm{ppm}$, and on the 40 non-exposed subjects (table 2). The data show that for most of the biomarkers studied no significant differences were found between the non-exposed subjects and those occupationally exposed to low concentrations of benzene; suggesting that they were unable to differentiate those exposed to less than $0.25 \mathrm{ppm}$ from those with only background exposure (table 2 ).

In the present study, benzene in blood was not measured for the non-exposed controls. Based on our earlier investigation ${ }^{9}$ of the same group, the mean (SD) concentration of benzene in blood for 25 non-smokers was $1.27(0.02)$ $\mathrm{nmol} / \mathrm{l}$. This is amost identical to the value of $1.26(0.03) \mathrm{nmol} / \mathrm{l}$ for the group exposed to low benzene concentrations (table 2 ). 

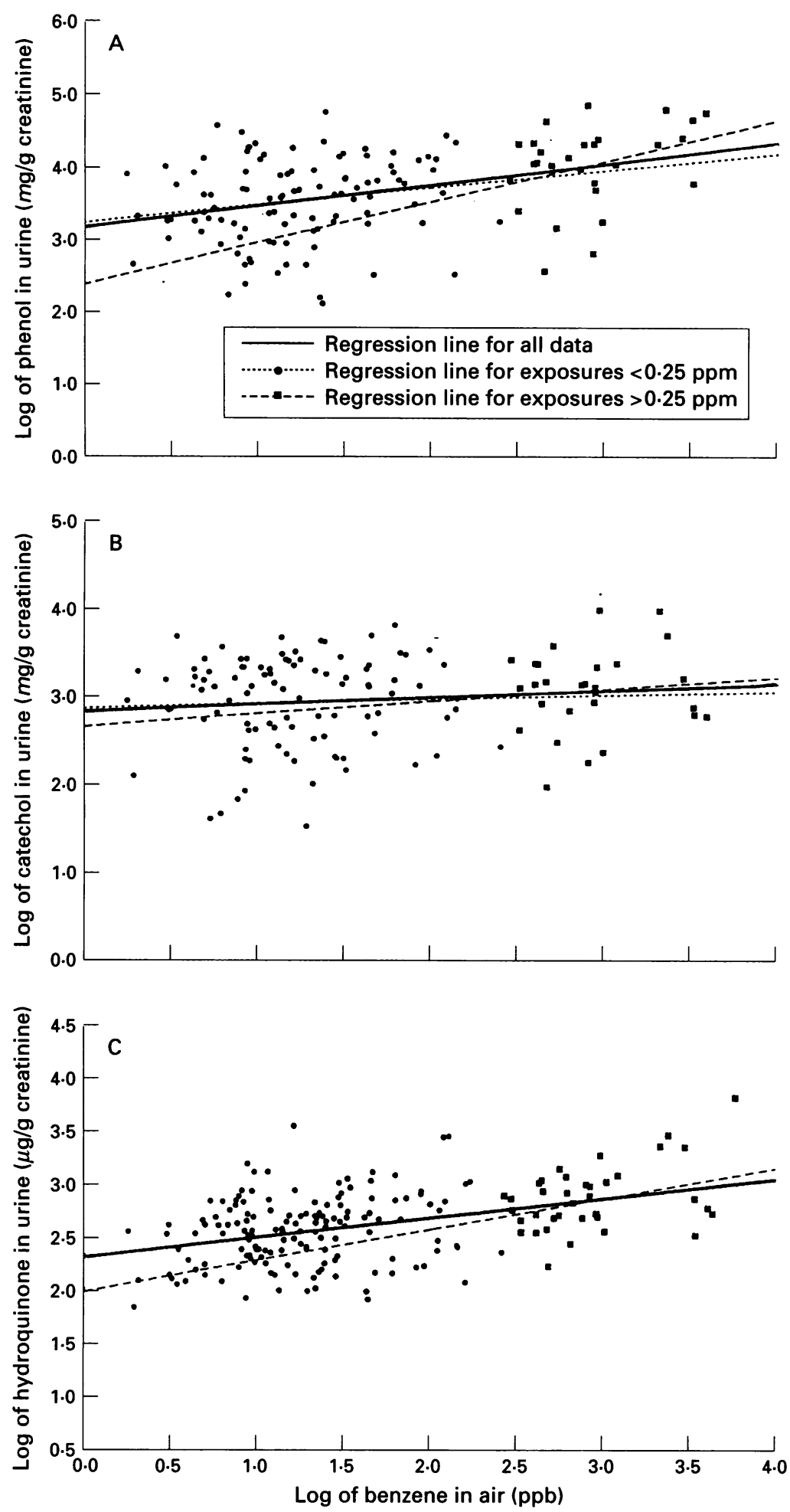

Figure 2 (A) Relation between urinary phenol and breathing zone air. $\log Y=0.51$ $\log X+0.09, n=131, r=0.38, P<0.05$. For subjects exposed to $<0.25 \mathrm{ppm}$, $r=0.18, N S$. For subjects exposed to $>0.25 \mathrm{ppm}, r=0.32$, NS. (B) Relation between urinary catechol and breathing zone air. $\log Y=0.21 \log X+0.96, n=131$, $r=0 \cdot 13$, NS. For subjects exposed to $<0.25 \mathrm{ppm}, r=0.04, N S$. For subjects exposed to $>0.25 \mathrm{ppm}, r=0 \cdot 10, N S$. (C) Relation between urinary hydroquinone and breathing zone air. $\log Y=1.01 \log X-1 \cdot 07, n=131, r=0.44, P<0.01$. For subjects exposed to $<0.25 \mathrm{ppm}, r=0.25 ;$ NS. For subjects exposed to $>0.25 \mathrm{ppm}, r=0.39$, $P<0.05$. recently developed biomarkers so that a biological exposure index corresponding to benzene exposure can be estimated. Evaluations were performed on unmetabolised benzene in blood and urine, trans, trans-muconic acid, and three major phenolic metabolites of benzene.

\section{UNMETABOLISED BENZENE IN BLOOD AND} URINE AS A BIOMARKER

For assessment of low level environmental exposure, the measurement of the unchanged parental compounds is usually of greater value as they tend to be rather specific. Although not many studies have been conducted on measurements of benzene in blood or urine, good correlation between blood or urinary benzene concentrations and environmental exposures has been reported. ${ }^{89}$ The results from the present study also show that benzene in blood and urine are more sensitive than other biomarkers of benzene exposure, however there are some shortcomings in term of application and cost.

(1) Owing to the high volatility of benzene, biological samples have to be analysed within a short period after sample collection.

(2) As benzene is ubiquitous, it is usually difficult to avoid contamination in the field.

(3) A photoionisation detector is required for detection of traces of benzene. Unfortunately, the instrument is sophisticated and costly. Furthermore, it is also important to point out that just like other volatile organic solvents, only a very small proportion of absorbed benzene will not be metabolised and excreted in the urine. Table 2 shows that when the exposure levels were low $(<0.25 \mathrm{ppm})$ this marker was unable to show significant difference from the controls. In short, the measurement of benzene in biological fluids seems to be promising, but its use for routine monitoring of low level exposure requires further validation.

PHENOLIC METABOLITES AS BIOMARKERS

The main metabolite of benzene, phenol, is by far the most widely investigated and well documented variable for biological monitoring of benzene. In a recent study we have shown that although there was a good correlation between phenol and environmental benzene, this variable was not specific for concentrations below $5 \mathrm{ppm} .{ }^{15}$ The present investigations further show that measurement of urinary phenol is unreliable, especially for low levels of benzene exposure (table 2). These findings suggest that if urinary phenol is used as a biomarker of benzene exposure for TWA of $5 \mathrm{ppm}$ or lower, it is limited by the inadequate specificity.

Relatively few studies have been conducted to examine the relation between urinary hydroquinone and benzene exposure. In an earlier study we have shown that there was a good statistical correlation between hydroquinone excretion and benzene exposure in the concentration range of 1 to $68 \mathrm{ppm} .{ }^{15}$ The present study confirms that there was a good correlation between benzene in air and hydroquinone for concentrations above $0.25 \mathrm{ppm}$ 


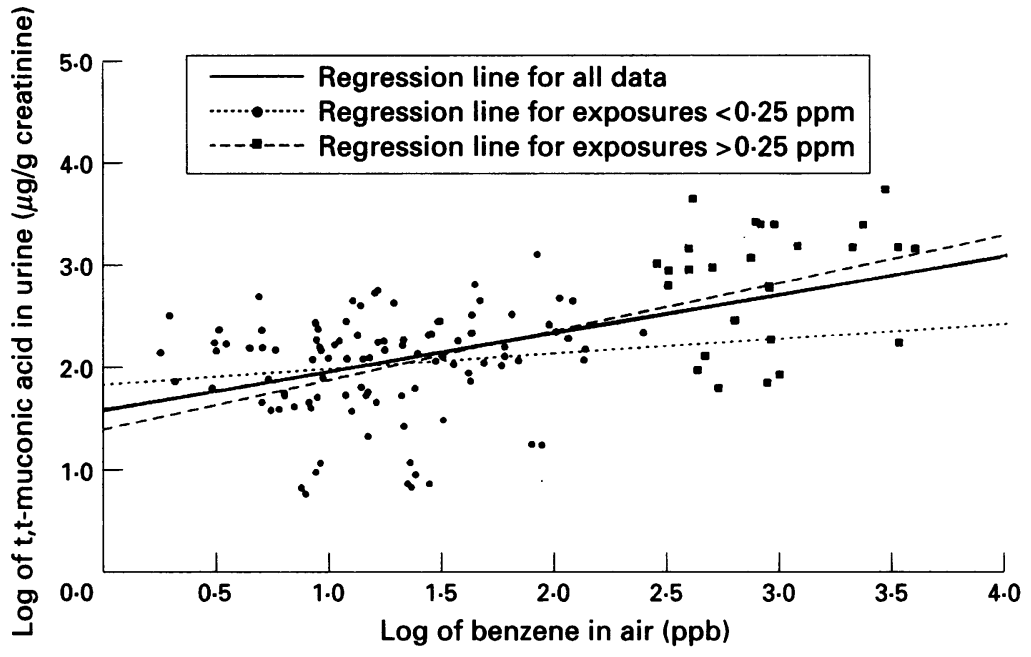

Figure 3 Relation between urinary trans, trans-muconic acid and breathing zone air. $\log Y=0.69 \log X+0.09, n=131, r=0.53, P<0.01)$. For subjects exposed to $<0.25$ ppm, $r=0.14 ;$ NS. For subjects exposed to $>0.25$ ppm, $r=0.55, P<0.05$.

(fig 2C). Nevertheless, we were unable to show that this biomarker is able to differentiate exposures of less than $0 \cdot 25 \mathrm{ppm}$ of benzene from no exposure (table 2).

Measurement of catechol in urine may be considered as complementary to phenol in urine as catechol is a metabolite derived from phenol through further oxidation. In the present study, however, we are unable to show any significant correlation between urinary catechol and benzene exposure (fig $2 \mathrm{~B}$ and table 2). This finding is similar to an earlier report showing that catechol was a poor biomarker for benzene exposure of concentrations from 1 to $68 \mathrm{ppm} .^{15}$ Its use as a biomarker for benzene exposure is thus limited.

TRANS, TRANS-MUCONIC ACID AS A BIOMARKER Earlier evidence has suggested that trans, trans-muconic acid could be used as a biomarker for benzene exposure. ${ }^{12-15}$ The results here further show that among all the metabolites studied, trans, trans-muconic acid correlates best with atmospheric benzene. Figure 3 shows that trans, trans-muconic acid is sensi- tive and specific for benzene exposure in the concentration range of 0.25 to $3.5 \mathrm{ppm}$. $(r=$ $0.55, \mathrm{P}<0.05)$. Nevertheless, similar to other biomarkers, when the exposure was less than $0.25 \mathrm{ppm}$, no significant exposure-response relation could be established (fig 3, $r=0.14$, $P<0.05$, table 2).

\section{EVALUATION OF VARIOUS BIOMARKERS}

The ideal biomarker for benzene exposure should be specific, reliable, and available for analysis with non-invasive techniques, detectable in trace concentrations, and most importantly quantitatively related to the degree of exposure. The overall results from the present investigations indicate that among the six biomarkers unmetabolised benzene in urine correlated best with environmental benzene (fig 2B). Its use as a biomarker of exposure to low concentrations of benzene is promising, however further studies are needed to overcome some of the technical limitations mentioned earlier.

The present results show that there are significant correlations between hydroquinone or trans, trans-muconic acid with benzene exposure, even at concentrations around $0.5 \mathrm{ppm}$ (fig 2C, $r=0.39, \mathrm{P}<0.05$, and fig $3, r=$ $0.55, \mathrm{P}<0.05)$. The application of trans, trans-muconic acid and hydroquinone as biomarkers could be of importance to health, particularly in predicting the effect induced by benzene. As trans, trans-mucoaldehyde, a precursor of trans, trans-muconic acid, and hydroquinone are highly myelotoxic, ${ }^{20-22}$ their use as biomarkers would thus better reflect the biologically active components of benzene metabolites.

Nevertheless, based on the present study, although there was a quantitative increase in relation to the degree of benzene exposure, the data fail to indicate that trans, trans-muconic acid can differentiate lack of exposure from occupational exposure to concentrations less than $0.25 \mathrm{ppm}$ (table 2).

It is interesting to note from a recent study that showed that although both S-phenylmercapturic acid and trans, trans-muconic acid were useful for monitoring benzene exposure, their use for detection at $0.3 \mathrm{ppm}$ or less was

Table 2 Means (SDs) of various biomarkers according to levels of exposure

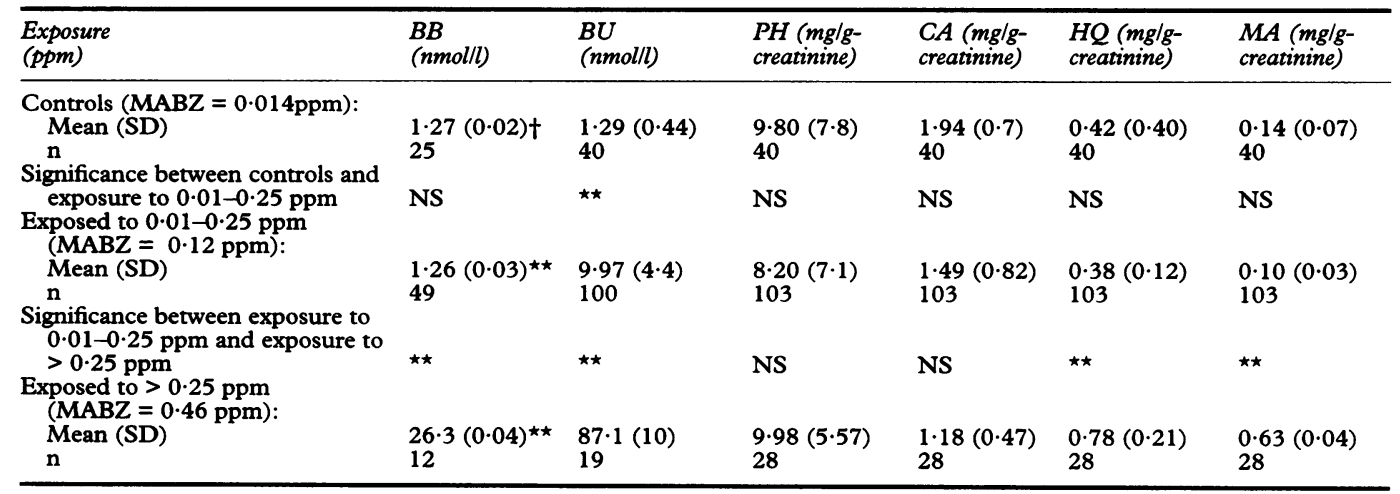

$\star \star P<0.01$.

†Data not available from the present study, this value is based on 25 of the same 40 subjects studied earlier. ${ }^{9}$

$\mathrm{MABZ}=$ mean concentration of air benzene; $\mathrm{BB}=$ benzene in blood; $\mathrm{BU}=$ benzene in urine; $\mathrm{HQ}=$ hydroquinone; $\mathrm{CA}=$ catechol; $\mathrm{PH}=$ phenol; $\mathrm{MA}=$ trans, trans-muconic acid 
reduced by interference from high background noise. ${ }^{11}$ The noise was probably due to either dietary intake or influence by coexposure to other aromatic hydrocarbons. ${ }^{11}$ This evidence together with the present findings suggest that caution has to be taken if these biomarkers are to be used for monitoring benzene of $0.3 \mathrm{ppm}$ or less.

It is important to mention that the present study was carried out among workers in a petroleum refinery. The workers were exposed to numerous other volatile compounds as well as benzene. Several of the aromatic hydrocarbons in petrol are known to have either antagonistic or synergistic effect of coexposure to benzene. Furthermore, several earlier studies have shown that cigarette smoking was associated with higher concentrations of benzene metabolites in the urine. ${ }^{1116}$ In the present study smokers were not included in the analyses, in depth validation will also be required to evaluate the potential influence of cigarette smoking on these biomarkers.

\section{Conclusion}

In summary, this paper evaluates the six biomarkers that have been suggested for biological monitoring of benzene exposure. The results showed that unmetabolised benzene is a sensitive biomarker and the concentration in urine correlates best with benzene exposure. However, owing to several technical drawbacks its use for routine measurement is likely to be limited. Among the metabolites of benzene, trans, trans-muconic acid and hydroquinone seem to be more reliable than the phenolic metabolites of benzene. With the decrease in environmental exposure and the low specificity of urinary phenolic compounds, it is expected that measurement of phenolic metabolites would become less significant. The results also indicate that caution has to be taken if trans, trans-muconic acid is to be used for benzene concentrations of $0.25 \mathrm{ppm}$ or less.

The overall findings tend to suggest that most of the currently available biomarkers are unable to provide sufficient specificity for monitoring benzene below $0.25 \mathrm{ppm}$.

We are grateful for the participation of the workers and the cooperation of the managements in the five major refineries in cooperation of the managements in the five major refineries in University of Singapore (Grant No 920387) and the Ministry
Ungapore of Labour, Singapore. We thank WK Au and EK Tan for their technical assistance and $3 \mathrm{M}$ Singapore for the passive dosimeters.

1 Yardley-Jones A, Anderson D, Parke D. The toxicity of benzene and its metabolism and molecular pathology in human risk assessment. Br F Ind Med 1991;48:437-44.

2 Rinsky RA. Benzene and leukemia: an epidemiologic ris assessment. Environ Health Perspect 1989;82:189-92.

3 Environmental Health Executive. Occupational exposure limits. London: HMSO, 1994. (EH40/94.)

4 American Conference of Governmental Industrial Hygienists. Notice of intended changes-benzene. Appl Occup Environ Hyg 1990;5:453-9.

5 Ong CN, Lee BL Determination of benzene and its metabolites: application in biological monitoring of environmental and occupational exposure to benzene. $f$ Chromatogr 1994;660:1-22.

6 Inoue $\mathrm{O}$, Seiji $\mathrm{K}$, Kasahara $M$, Nakatsuka $H$, Watanabe $T$, Yin SG, et al. Determination of catechol and quinol in the urine of workers exposed to benzene. $\mathrm{Br} F$ Ind $\mathrm{Med}$ 1988;45:487-92.

7 Lee BL, Ong HY, Shi CY, Ong CN, Simultaneous determination of hydroquinone, catechol and phenol in urine using high-performance liquid chromatography with fluorimetric detection. $\mathcal{F}$ Chromatogr 1993;619:259-66.

8 Ghittori S, Fiorentino ML, Maestri L, Cordioli G, Imbriani $M$, Urinary excretion of unmetabolized benzene as an indicator of benzene exposure. $\mathcal{F}$ Toxicol Environ Health 1993;38:233-43.

$9 \mathrm{Kok}$ PW, Ong CN. Blood and urinary benzene determined by headspace gas chromatography with photoionization by headspace gas chromatography with photoionization
detection. Int Arch Occup Environ Health 1994;66: detection.

10 van Sittert NJ, Boogaard PJ, Beulink GDJ. Application of the urinary S-phenylmercapturic acid test as a biomarker for low levels of exposure to benzene in industry. $\operatorname{Br} \mathcal{F}$ Ind Med 1993;50:460-9.

11 Boogaard PJ, van Sittert NJ. Biological monitoring of exposure to benzene: a comparison between $S$-phenyl mercapturic acid, trans, trans-muconic acid, and phenol. Occup Environ Med 1995;52:611-20.

12 Inoue $\mathrm{O}$, Seiji $\mathrm{H}$, Nakasuka $\mathrm{T}$, Watanabe $\mathrm{SN}$, Yin $\mathrm{SN}, \mathrm{Li}$ $\mathrm{GL}$, et al. Urinary tt-muconic acid as an indicator of exposure to benzene. Br 7 Ind Med 1989;46:122-7.

13 Lee BL, New AL, Kok PW, Ong HY, Shi CY, Ong CN Urinary trans, trans-muconic acid determined by liquid chromatography: application in biological monitoring of benzene exposure. Clin Chem 1993;39:1788-92.

14 Lauwerys RR, Buchet JP, Andrien F. Muconic acid in urine: a reliable indicator of occupational exposure tobenzene. Am f Ind Med 1994;25:297-300.

15 Ong CN, Kok PW, Lee BL, Shi CY, Ong HY, Chia KS, $e$ al. Evaluation of biomarkers for occupational exposure to benzene. Occup Environ Med 1995;52:528-33.

16 Ong CN, Lee BL, Shi CY, Ong HY, Lee HP. Elevated levels of benzene-related compounds in the urine of cigarette smokers. Int 7 Cancer 1994;59:177-80.

17 Ong CN, Chia SE, Phoon WH, Tan KT. Biological monitoring of occupational exposure to tetrahydrofuran. $\mathrm{Br} F$ Ind Med 1991;48:616-21.

18 Ghittori S, Imbrani E, Pezzagno G, Capodaglio E. The urinary concentrations of solvents as a biological equivalent exposure limit for nine solvents. Am Ind Hyg Assoc $\mathcal{F}$ 1987;48:786-90.

19 Boeniger MF, Lowry LK, Rosenberg J. Interpretation of urine results used to assess chemical exposure with emphasis on creatinine adjustment: a review. Am Ind Hyg Assoc $\mathcal{F}$ 1993;54:615-27.

20 Witz G, Gad SC, Tice RR, Oshiro Y, Piper CE, Goldstein BD. Genetic toxicity of the benzene metabolites trans, trans-mucoaldehyde in mammalian and bacterial cells. Mutat Res 1990;240:295-306.

21 Irons RD, Stillman WS, Colagiovanni DB, Henry VA Synergistic action of the benzene metabolite hydroquinone on myelopoietic stimulating activity of granulocyte/macrophage colony-stimulating factor in vitro. Proc Nat Acad Sci US A 1992;89:3691-5.

22 Sze CC, Shi CY, Ong CN. Cytotoxicity and DNA strand breaks induced by benzene and its metabolites in Chinese hamster ovary cells. $\mathcal{f}$ Appl Toxicol (in press). 